\title{
A Social Hypertext Model for Finding Community in Blogs
}

\author{
Alvin Chin \\ Interactive Media Lab \\ Department of Computer Science \\ University of Toronto \\ Toronto, ON, Canada \\ achin@cs.toronto.edu
}

\author{
Mark Chignell \\ Interactive Media Lab \\ Department of Mechanical and Industrial Engineering \\ University of Toronto \\ Toronto, ON, Canada \\ chignell@mie.utoronto.ca
}

\begin{abstract}
Blogging has become the newest communication medium for creating a virtual community, a set of blogs linking back and forth to one another's postings, while discussing common topics. In this paper, we examine how communities can be discovered through interconnected blogs as a form of social hypertext [14]. We propose a method and model that detects structures of community in the social network of blogs by integrating McMillan and Chavis' sense of community [26] along with network analysis [8, 11]. From the model, we measure community in the blogs by aligning centrality measures from social network analysis [17] with measures of sense of community obtained using behavioural surveys. We then illustrate the use of this approach with a case study built around an independent music blog. The strength of community measures were found to be well aligned with the network structure, based on centrality measures. Even though the sample size from the case study was small, once the structure and measure of communities are calibrated according to our social hypertext model, communities can be automatically found and measured for other blogs without the need for behavioural surveys.
\end{abstract}

\section{Categories and Subject Descriptors}

H.1.2 [Models and Principles]: User/Machine Systems - Human factors, Human information processing. H.3.5 [Information Storage and Retrieval]: Online Information Services - Webbased services. H.5.4 [Information Interfaces and Presentation]: Hypertext/Hypermedia - Architectures, Theory. J.4. [Social and Behavioural Sciences]: Sociology.

\section{General Terms}

Measurement, Human Factors.

\section{Keywords}

Blogs, social networks, hypertext, virtual community, sense of community

\footnotetext{
Permission to make digital or hard copies of all or part of this work for personal or classroom use is granted without fee provided that copies are not made or distributed for profit or commercial advantage and that copies bear this notice and the full citation on the first page. To copy otherwise, or republish, to post on servers or to redistribute to lists, requires prior specific permission and/or a fee.

HT'06, August 22-25, 2006, Odense, Denmark.

Copyright 2006 ACM 1-59593-417-0/06/0008...\$5.00.
}

\section{INTRODUCTION}

Hypertext is typically conceptualized as a network of linked documents, where the links between documents are referred to as hyperlinks, providing a means of navigating/browsing through the network by selecting a path of links through the documents. Social networks are analogous aggregations of interconnected people. Formally, networks of people and networks of documents can both be described by graphs, with nodes and edges/links as common abstract representations of each type of network.

The world's largest hypertext is the World Wide Web, with billions of pages/documents. Blogs (Weblogs) represent special kinds of dynamic documents that contain periodic, reverse chronologically ordered posts on a common webpage. The format varies from simple bullet-lists of hyperlinks to article summaries with user-provided comments and ratings [38]. Typically, blogs are written by a single author and are closely identified with that person. Thus, a blog functions as an amalgam of document and person, and blogs link hypertext networks with social networks. In addition, people can comment on blogs, thereby creating an explicit link from themselves to the blog. By treating people as synonymous with the blogs that they author, comments that people make on each other's blogs may then be viewed as reciprocal links in a social network. The patterns of interconnections between large numbers of blogs thus forms a social hypertext, and this social hypertext not only conveys hyperlinked information, but also may create forms of virtual community as people establish online presences and locales, and communicate with each other, through webs of interconnected blogs.

Social bookmarking systems such as del.icio.us and Dogear represent related forms of social hypertext that link information networks with social networks. In this paper we examine interconnected blogs as a form of social hypertext and outline techniques for measuring strength of community within blogs. It is anticipated that these measures may also be applied to social hypertext networks constructed from related techniques such as social bookmarking. We propose a method for aligning centrality measures based on social network analysis with strength of community measures obtained using behavioural surveys. We then illustrate the use of this approach with a case study built around a research blog.

Our contributions are the following. First, we propose a model for finding community in blogs that take into account blogging behaviour, in addition to link analysis and social network analysis. Second, we attempt to integrate both behavioural approaches to studying community, along with network and link 
analysis approaches, which other researchers have only done separately. This allows us to calibrate structures for community that can be used to automatically find and measure community in other blogs without the use of surveys. Third, we propose a measure for finding community that uses network centrality as a measure from social network analysis. The paper is organized as follows. Section 1 is the Introduction; Section 2 provides background and related work to blogs, communities and social networks; Section 3 presents our model for finding communities in blogs; and Section 4 applies that model to a case study. We make conclusions and recommendations in Section 5 and provide a list of references in Section 6.

\section{BACKGROUND}

This section reviews the literature on virtual communities and examines how sense of community can be used as a model and measure for community. We also review some network analysis measures that may be related to strength of community.

\subsection{Identifying Virtual Communities}

According to the Wikipedia, "A community is an amalgamation of living things that share an environment... In human communities, intent, belief, resources, preferences, needs...may be present and common..., but the definitive driver of community is that all individual subjects in the mix have something in common." [39]. There have been many studies dealing with identifying characteristics of community in physical environments such as healthcare [24], urban environments [10], organizations [31], and neighbourhoods [37]. Results from these studies indicate that physical community is identified by the physical location that delineate the community, along with defined characteristics and established norms that characterize the community.

\subsubsection{Virtual community}

Finding community in virtual (as against physical), environments such as e-mail and the web is more difficult because there is no physical location and no physical human interaction to observe. Despite this, there is a wealth of literature demonstrating that communities do exist in them $[1,3,20,22,23,25,29,30,36]$. Virtual communities has been described by Rheingold as "social aggregations that emerge from the Net when enough people carry on those public discussions long enough, with sufficient human feeling, to form webs of personal relationships in cyberspace" [29]. Virtual communities are considered important for social reasons [36]. People tend to reap the benefits of social relationships with like-minded others as they become more connected with others through virtual communities.

\subsubsection{Finding virtual community in blogs}

A few studies have looked into identifying virtual communities in blogs [4, 12, 13, 21, 27, 34]. One method that researchers commonly use is content analysis which examines the content of blog posts and comments for evidence of virtual community. Wei [34] recorded the statistics of a knitting blog in order to find norms that indicated membership rules as an indicator of community. Nardi et al. [28] performed text analysis on bloggers' posts and comments in order to identify feelings of community. Another method is to observe participants of a blog through interviews and surveys. From the same study, Nardi et al. audio taped interviews with bloggers and administered surveys.
They analyzed the responses from bloggers for the existence of community interactions. However, content analysis and participant interviews and surveys are highly subjective, time consuming and error prone.

An alternative approach is to use clustering algorithms to automatically find communities in blogs. Since blogs are web pages, web search algorithms can be used to extract communities. For example, Kleinberg used the concept of hubs and authorities [23] in order to identify authorities (who are considered experts on the topic) as communities. A hub is a page which has a collection of links to pages about that topic, while an authority is a page which has relevant information about the topic. Kumar [22] expanded on hubs and authorities by using co-citation as a way to extract all communities on the web and used graph theory algorithms to identify all instances of graph structures that indicate community. Other researchers such as Flake [16] have also used connectivity and graph theory for identifying web communities. Merelo-Guervos et al. use a pattern and data mining algorithm called Kohonen's Self-Organizing Map to group communities into cells. Since community is an evolutionary process, the discovery of communities can be improved by exploiting the time structure inherent in blogs. Kumar [21] applied Kleinberg's bursty algorithm to identify communities as bursts of hyperlinks between blogs where the bursts are obtained from the time graph extracted from the blog graph as a result of crawling the blogs. However, while there are many clustering algorithms that can be used to discover properties related to the construct of community, they need to be validated and calibrated against the amount of community actually experienced by participants. In addition, mappings need to be identified between relevant algorithms and the subscales or dimensions within the overall community construct that they actually measure.

\subsection{Sense of Community}

To measure and calibrate community, established methods from psychology and sociology can be used for finding community in physical communities such as face-to-face meetings and organizations [7], or in virtual communities like e-mail [32] and newsgroups [5]. One common theme that emerges is that members of a community experience a "sense of community" (SOC) in which there is a "feeling that members [of a group] have of belonging, a feeling that members matter to one another and to the group, and a shared faith the members' needs will be met through their commitment to be together" [26]. According to McMillan and Chavis, there are four features of sense of community. First, there are feelings of membership where a member has a feeling of belonging to, and identifying with the group. Second, there are feelings of influence where a member has feelings of having influence on and being influenced by the community that emerge from enforcing and challenging norms within the group. Third, there are feelings of reinforcement of needs in which a member feels support from others, has status in the group, and meets other people's needs while having her own needs met. Fourth, there are feelings of shared emotional connection where members feel that they have a relationship and a shared connection with others due to frequent and high quality interaction. McMillan and Chavis devised a method for determining sense of community by creating a list of 12 questions [9] and from those questions, he created sense of community subscales to calculate scores for membership, influence, reinforcement of needs, and shared emotional connection. 
Even though there are few studies of sense of community in virtual communities, evidence of membership, influence, reinforcement of needs, and shared emotional connection, have been identified according to Blanchard and Markus [5]. Blanchard adapted the SOC subscales and questions to blogs in her study of sense of community in the Julie/Julia blog [4] and in the Multiple Sports Newsgroup [5]. However, Blanchard found that in order for a blog to be a virtual community, it had to exhibit the characteristics of a "virtual settlement", that is, a virtual place in which people interact by examining artifacts (analogous to digging for artifacts in archaeology), as first described by Jones [19]. Efimova and Hendrick [12] explored virtual settlements where they used blog reading patterns, linking patterns, blog conversations, and blogger directories as artifacts for indicators of blog community. They started from Efimova's blog, identified blogs linked frequently from it, and then used their artifacts to filter out those blogs that would not be part of a community. Our work is mostly related to Blanchard's study of sense of community in the Julie/Julia blog where we adapt the sense of community subscales and use sense of community for our definition of community. In addition, our work is similar to Efimova and Hendrick's study of artifacts in a virtual settlement where we also employ link patterns. However, rather than recording links to blogrolls and links in the text of blogs, we use the commenter's blog URL (if provided) when commenters make comments. We feel that the commenter's blog URL is a more reliable indicator of social interaction among bloggers compared to URLs embedded in the blog text of posts and comments, because the commenter's blog URL indicates a conversational relationship between the commenter and the blog author.

However, sense of community subscales for sense of community and observing artifacts in a virtual settlement, do not take into account the structural linking behaviour that is inherent in the commenting features of blogs. Therefore, social networks formed by groups of blogs that link to and comment on each other, may provide additional insight into community formation in blogs.

\subsection{Network Analysis}

Structural analysis of networks is a promising technique that may provide extremely useful information about community. It has the advantage of being able to be carried out in an automated fashion, and on a large scale. However, proposed linkages between structural analytic measures and measures of community need to be validated. Landmarks represent a node-level concept that appears to be related to network structure. Valdez and Chignell [33] showed that number of second-order inlinks (i.e., the number of nodes that pointed to the node of interest with path 2) can serve as a measure of landmark quality.

Communities can be thought of as a multi-node analogue of landmarks on the Web. The interlinking between blogs is used as a way to indicate relationships and to determine conversations that can potentially identify communities [12, 18]. Social network analysis (or network analysis) exploits the link structure and examines the roles and behaviour of nodes on other nodes in the network, and on the network as a whole. Using tools such as UCINET [6] and Pajek [11], social networks can be visualized and measures potentially related to aspects of community, can be calculated.

Network analysis has been used to study the relationships and structure of networks in e-mail, newsgroups and the web.
Network centrality [17] can be used to measure community in networks such as a blog, since it is a measure of how important or central an individual node is to the network. Specifically, degree centrality, closeness centrality and betweenness centrality can be used as community measures. Degree centrality measures the number of direct connections to other nodes so the nodes with high degree centrality could possibly be nodes to focus on in community building. Closeness centrality measures how many steps on average it takes to reach every other node in the network, therefore nodes with high closeness centrality can most efficiently make contact with other nodes and thus be candidates for community. Betweenness centrality measures the extent to which a node can act as an intermediary or broker to other nodes, thus nodes with high betweenness centrality could indicate brokerage to other communities.

A number of researchers have proposed using network analysis as a method for identifying community. However, there is no universal consensus as to which measures may be most closely related to different aspects of community. Tyler et al. [32] used an algorithm based on betweenness centrality in order to automatically discover communities in e-mail. Fisher did not identify communities per se, but analyzed newsgroups in Usenet using ego-centric networks and degree distribution [15] to look for social structure in Usenet newsgroups and conversational structure. Efimova et al. [13] visualized the social network in their blog dataset of knowledge management blogs using Pajek, however they did not compute the degree distribution or centrality. Herring et al. [18] identified A-list blogs (the most cited blogs that appear as the top 100 in 2 out of 3 ranking systems) and used them as the seed or core from which the network was grown to include other blogs that linked to those Alist blogs. They visualized the network in Pajek and used social network analytic measures of overlap, distance, reciprocity (bidirectional links), in-degree (number of blogs that link to the target blog) and out-degree (number of blogs that link from the target blog), to identify conversational patterns. Our work closely resembles Efimova et al. but differs in that we compute centrality measures, identify structural patterns of community, and use SOC measures. Our work differs from Herring et al. in that we do not identify A-list blogs to grow community, but rather, we start with an initial blog (like Efimova et al.) from which we use the links from the social network to identify structures that can form community.

However, the previous studies do not appear to have any formal methodology from which communities are identified, and lack any measurement and validation of community. In our paper, we present a formal approach that looks for explicit and wellcalibrated mappings between social network analytic measures and the corresponding sense of community that is experienced by the readers and authors of the associated blogs.

\section{SOCIAL HYPERTEXT MODEL FOR FINDING COMMUNITY IN BLOGS}

Blogs are linked into a social hypertext just like the World Wide Web [14], both by explicit links from one blog to another and by comments made by one blog author to the postings on another blog, which can be interpreted as links. In this section, we discuss methods for finding community in a set of related blogs, based 
both on McMillan and Chavis' definition of sense of community (SOC) and on interpretation of the network structures formed by groups of inter-connected blogs. We first describe a conceptual framework within which these methods can be used to identify community within blogs.

\subsection{Conceptual Framework}

An initial approach to identifying and measuring community in blogs was presented by the authors in [2], where techniques for motivating sense of community based on shared topics of interest, were discussed. In the methodology presented below, we use McMillan and Chavis' definition of sense of community [26] and network analytic measures of centrality [17] for finding communities in blogs.

\subsection{Research Methodology}

Figure 1 illustrates the methodology used to evaluate community in blogs so that the resulting feedback can be used to enhance the strength of community within groups of blogs.

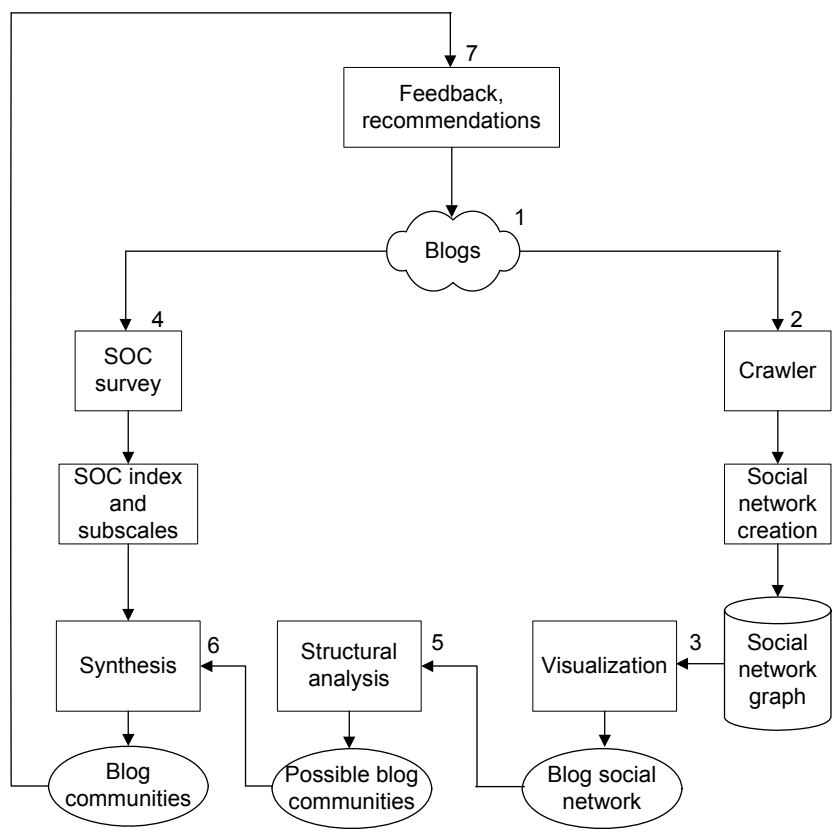

Figure 1. Methodology for identifying and calibrating blog community

The methodology is divided into seven steps. Step 1 involves finding candidate blogs to examine for possible signs of community. These are blogs that have the potential to motivate the bloggers to create a community as explored in our earlier work [2]. Once we have found the blogs that we wish to find community in, Step 2 involves crawling the blogs and recording the links between blogs through posts and comments. The resulting set of blog traces is processed and converted into a social network, represented as a graph. In Step 3, we visualize the social network for the candidate blogs using the Pajek software [11]. In step 4, we administer a sense of community survey that asks questions to the bloggers about feelings of sense of community as described in Section 2.2. We apply the SOC index and subscales to produce SOC scores of membership, influence, reinforcement of need and shared emotional connection, along with a total sense of community score. Then, in step 5, we identify possible blog communities through structural analysis, with a focus on measures of centrality. In step 6 , we synthesize the SOC scores and network analytic measures of centrality to determine which blogs could be part of a community. Finally, in step 7, the set of identified blog communities is provided as feedback to the candidate blogs and used to recommend new links between blogs in order to grow communities within the social hypertext. It is important to note that the SOC survey and SOC index and subscales referred to in Figure 1, are only used for initial calibration of community measures and structures based from a sample of the blogs. For all other blogs, a sense of community survey is not needed and community structures and measures will be derived from the calibrated results. Further details concerning the social hypertext indicators subsumed within this model are discussed in Section 3.3.

\subsection{Social Hypertext Indicators}

What characteristics and indicators can be used to detect a sense of community within blogs? One approach is to visualize the social network, and thereby identify structures that indicate a characteristic from the sense of community. The resulting indicators are referred to as visualization indicators in Table 1. The information provided by visualization indicators can be supplemented by social network analysis indicators. Sense of community measures can then be aligned with the visualization indicators and social network analysis indicators as shown in Table 1. In its alignment of visualization and social network analysis indicators with the four SOC characteristics, Table 1 may be thought of as an expansion of the synthesis step (6) shown in Figure 1 .

Table 1. Social hypertext model for identifying sense of community in blogs

\begin{tabular}{|c|c|c|}
\hline SOC characteristic & $\begin{array}{l}\text { Visualization } \\
\text { indicator }\end{array}$ & $\begin{array}{l}\text { Social network } \\
\text { analysis indicator }\end{array}$ \\
\hline Membership & $\begin{array}{l}\text { Reciprocal links with } \\
\text { each directed link } \\
\text { having frequency } \geq k \\
\text { Star network } \\
\text { Hierarchical } \\
\text { reduction } \\
\text { Degree distribution }\end{array}$ & Degree centrality \\
\hline Influence & Brokers or bridges & $\begin{array}{l}\text { Betweenness } \\
\text { centrality }\end{array}$ \\
\hline $\begin{array}{l}\text { Reinforcement of } \\
\text { needs }\end{array}$ & $\begin{array}{l}\text { Reciprocal links } \\
\text { where each directed } \\
\text { link has frequency }> \\
m \text { where } m \text { is the } \\
\text { need threshold }\end{array}$ & $\begin{array}{l}\text { Closeness } \\
\text { centrality }\end{array}$ \\
\hline $\begin{array}{l}\text { Shared emotional } \\
\text { connection }\end{array}$ & $\begin{array}{l}\text { Triangles } \\
\text { Completely } \\
\text { connected graphs }\end{array}$ & $k$-cores \\
\hline
\end{tabular}

We describe in more detail how the visualization indicators and social network analysis indicators may be derived for each of the sense of community characteristics. 


\subsubsection{Membership}

In blogs, feelings of membership or membership ties can be represented by reciprocal links [12] in which a post by, for example, blogger $\mathrm{A}$ is commented on by blogger $\mathrm{B}$ (which is denoted by the link $\mathrm{A}->\mathrm{B}$ ), and blogger $\mathrm{B}$ writes a post on blog $\mathrm{B}$ which is commented by blogger A (which is denoted by the link B->A). Note that when B comments on A's blog, the result is a link on A's blog that points back to B, which is why comments create links that point from the blog back to the person/blog doing the commenting and not vice versa. This is visualized in Figure 2 as unidirectional links where $x$ and $y$ indicate the frequency of posts or comments that B made on A's blog and A made on B's blog, respectively, and simplified in Figure 3 as a reciprocal link.

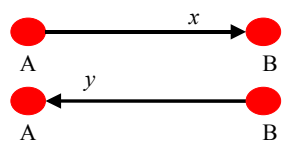

Figure 2. Unidirectional links for the reciprocal link

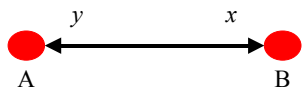

Figure 3. Reciprocal link of Figure 2 as bidirectional link.

If a blogger feels that she is a member of the community, then she will tend to have a connection to other members in the community, thus forming a star network structure as shown in Figure 4.

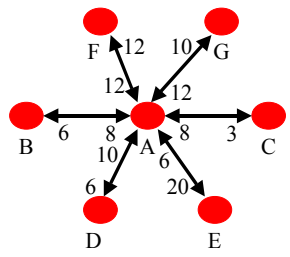

Figure 4. Star network as structure for membership in community

The frequency of each directional link in the reciprocal links comprising the star network should likely be greater than some number $k$ where $k$ can be interpreted as the threshold frequency at which a blog is considered a member of a community. $k$ is a variable which can in principle be determined empirically from the nature of the community or from analyzing the content of the blog conversations. Selecting the value of $k$ will determine the number and size of communities formed.

We determine which blogs could be members of a community by eliminating those that are not, using hierarchical reduction which recursively deletes from the network all nodes that have 0 or 1 neighbours. This simplifies the blog network and allows us to focus on those blogs that could be part of a community.

Using social network analysis, we use degree centrality as an indicator for membership. A node with high degree centrality has many direct connections with numerous other network nodes and can influence others. The degree centrality [17] can be calculated by the following formula (normalized between 0 and 1) as

$$
\mathrm{C}^{\prime}{ }_{\mathrm{D}}\left(\mathrm{n}_{\mathrm{i}}\right)=\underline{\mathrm{d}}_{\mathrm{i}}\left(\mathrm{n}_{\mathrm{i}}\right)
$$

where $C^{\prime}{ }_{D}\left(n_{i}\right)$ is the normalized degree centrality for the $\mathrm{i}^{\text {th }}$ node $n_{i}, d_{i}\left(n_{i}\right)$ is the degree for the $i^{\text {th }}$ node $n_{i}$, and $g$ is the total number of nodes in the network.

\subsubsection{Influence}

McMillan and Chavis [26] explain that influence in a community is bidirectional in nature, where members of a group feel empowered to have influence in the group while the group also has influence over its members. Therefore, reciprocal links can be considered as a structure for influence. A person can exert an influence on others in a community if that person is a member of other prominent communities. For example, in Figure 5, blogger $\mathrm{B}$ has an influence on blogger A and A's community because blogger B is connected to blogger A while also having her own community.

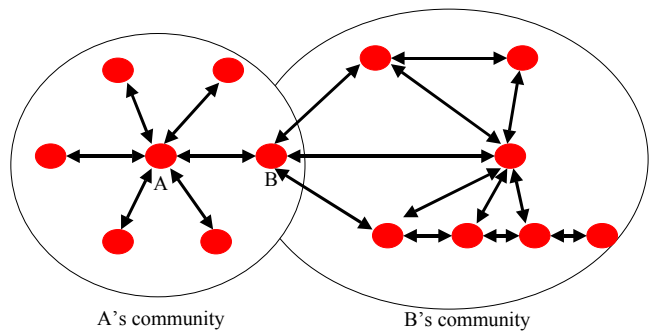

Figure 5. Example structure of influence where $B$ acts as a broker and $B$ can influence $A$

Therefore, B becomes a bridge or broker and blogs that act in the role of brokers are also likely to exert influence.

From social network analysis, one indicator for influence is betweenness centrality. This means that a blog with a high betweenness centrality exerts a high degree of influence on others in the community. Betweenness centrality is calculated from [17] as

$$
C_{B}\left(n_{i}\right)=\sum_{j} \sum_{\substack{k \\ j<\mathrm{k}}} \frac{g_{j k}\left(n_{i}\right)}{g_{j k}} \quad i \neq j \neq k
$$

where $C_{B}\left(n_{i}\right)$ is the betweenness centrality, and $g_{j k}\left(n_{i}\right)$ is the number of geodesics linking the two nodes $j$ and $k$ that contain node $i$. A geodesic is the number of links in the shortest possible walk from one node to another. Normalizing the result between 0 and 1 yields

$$
C_{B}^{\prime}\left(n_{i}\right)=\frac{C_{B}\left(n_{i}\right)}{[(g-1)(g-2)] / 2}
$$

where $C^{\prime}{ }_{B}\left(n_{i}\right)$ is the normalized betweenness centrality, $C_{B}\left(n_{i}\right)$ is the betweenness centrality, and $g$ is the total number of nodes in the network.

\subsubsection{Reinforcement of needs}

Bloggers will feel part of a community if they feel dependent on others close to them and their needs are satisfied by the community. We identify acknowledged interdependence by the frequency of the links. The higher the frequency of the link, then this can indicate that the blogger has a higher intensity of need. This may suggest that there is a threshold need frequency $m$ upon which a blogger shows that she exhibits a need from the conversations. The threshold need frequency is a subjective measure that can be calculated based on analyzing the sense of 
community subscale of need from McMillan and Chavis, and determining the corresponding frequency of connections for the membership links. The threshold need frequency is dependent on the nature of the blog, the depth of the conversations, the psychological nature of the bloggers, and the granularity of community which will be different for each blog.

Closeness centrality appears to be related to the construct of interdependence and reinforcement of needs. For example, a node $\mathrm{C}$ with high closeness centrality can efficiently make contact with other nodes in the network, so that if blog A connects to blog $\mathrm{C}$, then blog A can reach other blogs through blog C. Therefore, if blog $\mathrm{A}$ has a need, then $\mathrm{A}$ can contact $\mathrm{C}$ who can refer to one of the members of C's community.

Closeness centrality can be calculated from [17] as follows

$$
C_{C}\left(n_{i}\right)=\left[\sum_{j=1}^{g} d\left(n_{i}, n_{j}\right)\right]^{-1}
$$

where $C_{C}\left(n_{i}\right)$ is the closeness centrality for node $i, d\left(n_{i}, n_{j}\right)$ is the geodesic distance from node $i$ to node $j$, and $g$ is the total number of nodes. The normalized closeness centrality is then

$$
\begin{array}{r}
\mathrm{C}^{\prime}{ }_{\mathrm{C}}\left(\mathrm{n}_{\mathrm{i}}\right)=\underline{\mathrm{C}}_{\underline{\mathrm{C}}}\left(\underline{\mathrm{n}}_{\mathrm{i}}\right) \\
\mathrm{g}-1
\end{array}
$$

\subsubsection{Shared emotional connection}

One of the key features of shared emotional connection from McMillan and Chavis is spiritual bond. Intense clusters and interaction can indicate the existence of a spiritual bond. Intense clusters in blogs represent conversations and comparing them to face-to-face conversations, there may be a possibility of finding shared emotional connection. A completely connected graph, where a blog is connected to every other blog, can be a structure for shared emotional connection as shown in Figure 6.

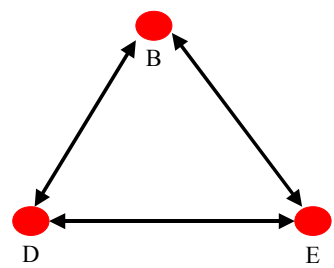

Figure 6. Example of completed connected graph as structure for shared emotional connection

Measures of cohesion are used in social network analysis to identify components that indicate intense clusters of interaction. We use $k$-cores to identify intense clusters. A $k$-core is a cluster where the minimum degree of each node in the cluster is at least $k$. This means that a $k$-core in a blog has at least $k$ conversations. Figure 7 shows an example of a $k$-core where $k$ is equal to 2 .

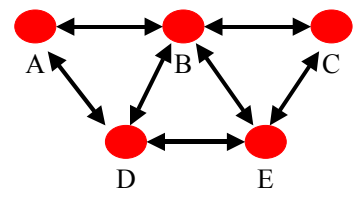

Figure 7. Example of a k-core where $k=2$

\section{CASE STUDY}

We apply our research methodology from Section 3.2 to a case study of an independent (indie) music blog. First, we describe the blog, the method for creating the social network, and the SOC survey that we created for determining sense of community in the blog and the SOC scores. Next, we identify sense of community from structural analysis using our social hypertext model from the previous section. From the SOC scores, we determine if there is a relationship between the sense of community score for a blog and its inclusion in the sense of community that we identified from the structural analysis. This allows us to refine the set of possible blog communities into definitive blog communities.

\subsection{Description of the Blog}

The first step in our research methodology from Figure 1 is to select the blog to analyze community in, which is the indie music blog. The indie music blog is a blog hosted on MSN Spaces that we created for Canadian independent musicians and their fans. This blog showcases upcoming indie music bands from an indie music website and is designed to promote and add value to the indie music virtual community. To stimulate interest and motivate community, we added a media player, photo album, custom lists, rating scheme, and song of the week.

Visitors can play, stop, and replay the featured song of the week, as well as other songs using the media player. A photo album shows pictures of artists, tours and concerts. We created custom lists to categorize and index music that we review by genre (ie. rock, pop, folk, etc.) and provide links to download the reviewed songs. This allows visitors to listen to songs and read reviews according to their favorite genre. We created a rating scheme to rate songs according to a five-point scale which encourages visitors to post their opinions in the comments, and select a particular song as the 'song of the week'.

\subsection{Creating the Blog Social Network}

From the second step of our research methodology in Figure 1, we created a blog crawler that crawled the indie music blog to two degrees of separation for inlinks (blogs that link to the target blog) and outlinks (blogs that link from the target blog). We used the RSS feeds of MSN Spaces blogs to crawl the indie music blog, the commenters of the indie music blog, and the commenters of the commenters of the indie music blog. RSS (Really Simple Syndication) is an XML format that aggregates entries from blogs and other syndicated web content which is made available for others to use. Crawling was restricted to MSN Spaces blogs because we found that the majority of commenters had their blogs on MSN Spaces, and we wanted to extract implicit communities from the MSN Spaces community.

As we crawled the blog, we recorded the blog URL of the blog that we crawled, as well as the blog URL of the commenter on the blog if it existed, in the format of (crawled blog URL, commenter's URL). Then, we computed the frequency for each record and anonymized the blog URLs. We created the social network from the results of the blog crawler into UCINET and visualized the network (step 3 of the research methodology) in Pajek.

The visualization of the network surrounding the indie music blog, as crawled on November 8, 2005, contained 604 blogs and is illustrated in Figure 8. 


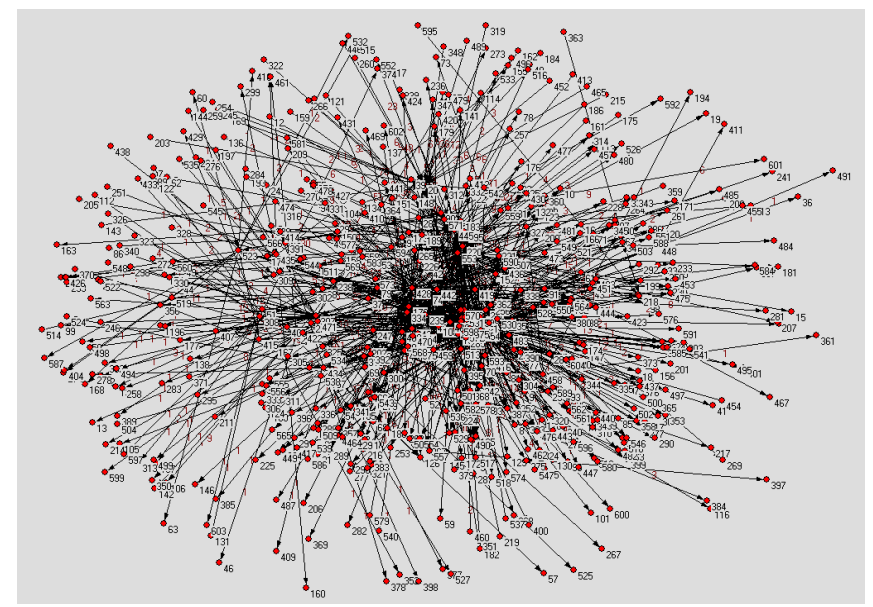

Figure 8. Network for the indie music blog up to 2 degrees of separation

\subsection{Identifying Sense of Community Using Sense of Community Index}

The fourth step in our research methodology from Figure 1 is to employ the sense of community survey. Before describing the results from the sense of community questions, we describe the demographics of the readers that responded to the survey, their internet usage and their blogging behaviour. By determining the demographic and behaviour of each reader that responded to the sense of community questions, we validate if the readers that we identify in the structural analysis step of the research methodology, could be actual blog communities.

\subsubsection{Blog reader demographics and behaviour}

The survey was posted online on the indie music blog and 15 people completed the survey. From the questions asking participants about their demographics and blogging behaviour, we found that participants were mostly young adults 21 to 30 years old with access to internet and use it frequently, were mostly blog readers rather than blog writers, and did not frequently make comments. As a result, these survey results, on a high level, suggest that there will not be many intense conversations in the network surrounding the indie music blog, which consequently means that there will be very few communities. If communities do exist, we postulate that they will be small and extremely focused. Even though the sample size for the survey is low and we cannot make concrete claims for definitive communities, nonetheless, this small number is advantageous for explicitly testing our social hypertext model. It is important to realize that the results that we present in the following sections are preliminary and are still part of exploratory work.

\subsubsection{Sense of community survey questions}

We adapted the questions from Chavis' sense of community index [9] to blogs, using a survey that was similar to the one that was administered in the Julie/Julia project by Blanchard [4]. We asked the blog readers a total of 12 questions and for each question, we provided a 5-point Likert answer scale of Strongly Disagree (1), Disagree (2), Agree and Disagree equally (3), Agree (4) and Strongly Agree (5).
Table 2. Sense of community survey questions

\begin{tabular}{|c|l|}
\hline $\begin{array}{c}\text { Question } \\
\text { code }\end{array}$ & Question \\
\hline Q1 & $\begin{array}{l}\text { I think this blog is a good one to read } \\
\text { Readers of this blog do not share the same } \\
\text { values } \\
\text { Other readers and I want the same thing from } \\
\text { this blog }\end{array}$ \\
Q3 & $\begin{array}{l}\text { I can recognize the names most readers who } \\
\text { post comments in this blog }\end{array}$ \\
Q4
\end{tabular}

SOC subscales were calculated for membership (Eqn. 6), influence (Eqn. 7), reinforcement of needs (Eqn. 8) and shared emotional connection (Eqn. 9) according to [9] as follows:

$$
\begin{gathered}
S O C_{\text {membership }}=\mathrm{Q} 4+\mathrm{Q} 5+\mathrm{Q} 6 \\
S O C_{\text {influence }}=\mathrm{Q} 7+\mathrm{Q} 8{ }^{\prime}+\mathrm{Q} 9 \\
S O C_{\text {needs }}=\mathrm{Q} 1+\mathrm{Q} 2{ }^{\prime}+\mathrm{Q} 3 \\
S O C_{\text {emotion }}=\mathrm{Q} 10+\mathrm{Q} 11^{\prime}+\mathrm{Q} 12
\end{gathered}
$$

For questions phrased negatively (Q2, Q6, Q8 and Q11), the score was reversed by subtracting 6 from the original score which resulted in Q2', Q6', Q8' and Q11' respectively. The total SOC index was calculated in Eqn. (10) by summing all the scores for the 12 questions as

$S O C_{\text {total }}=\sum_{j=1}^{12} Q_{j}+\sum_{k=2}^{12} Q^{\prime}{ }_{k} \quad \mathrm{j} \neq 2,6,8,11, k \neq 3,4,5,7,9,10,12$

\subsection{Visualizing Community Structure}

The sixth step in our research methodology of Figure 1, is to perform structural analysis to discover possible blog communities. We applied the indicators from our social hypertext model of Section 3.3 to identify structures that can indicate sense of community on the indie music blog network from Figure 8. For each characteristic of sense of community in Table 1, we used the visualization indicator and social network analysis indicator provided by Pajek to present the structures that indicate sense of community.

\subsubsection{Membership}

From Figure 8, we obtained a degree distribution to determine the degrees with the highest frequency and to identify any possible membership ties. Figure 9 shows the degree distribution for the indie music blog network. 


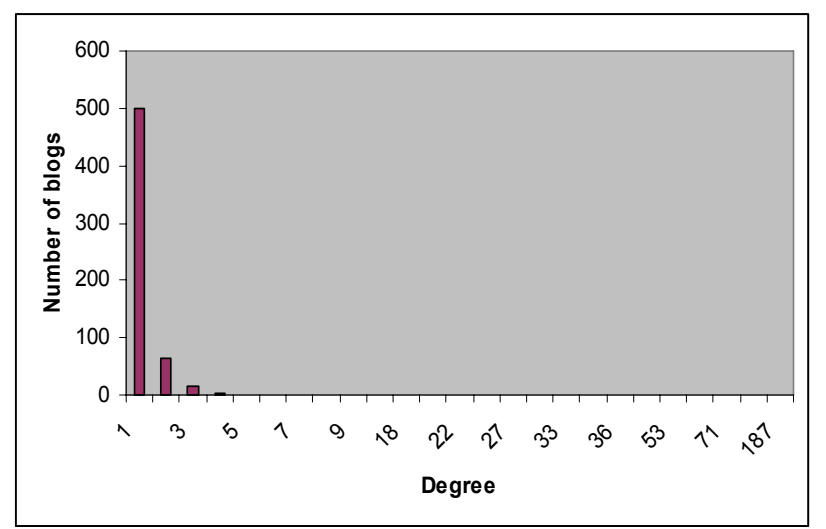

Figure 9. Degree distribution for indie music blog network

From Figure 9, we see that the degree distribution is one that is decreasing with 501 out of 604 blogs that have a degree of 1, 65 blogs that have a degree of 2, 14 that have a degree of 3, and 24 that have a degree of more than 3 . It is difficult to suggest that there is some type of community in this network so we then conducted an in-depth analysis using reciprocal links.

For reciprocal links, we visualized the blogs in Pajek that had a directed link of at least a frequency of 2 . We chose $k$ to be 2 because we felt that a frequency of 1 connection, in our opinion, was hardly any indication of community, therefore we decided to choose 2 as the minimum frequency. We then converted the directed links into reciprocal links by summing the frequencies of each directed link in the reciprocal link. Next, we performed a hierarchical reduction to remove all blogs with 0 or 1 neighbours. This resulted in the network of Figure 10 with 54 nodes and the indie music blog as node 29 in the center.

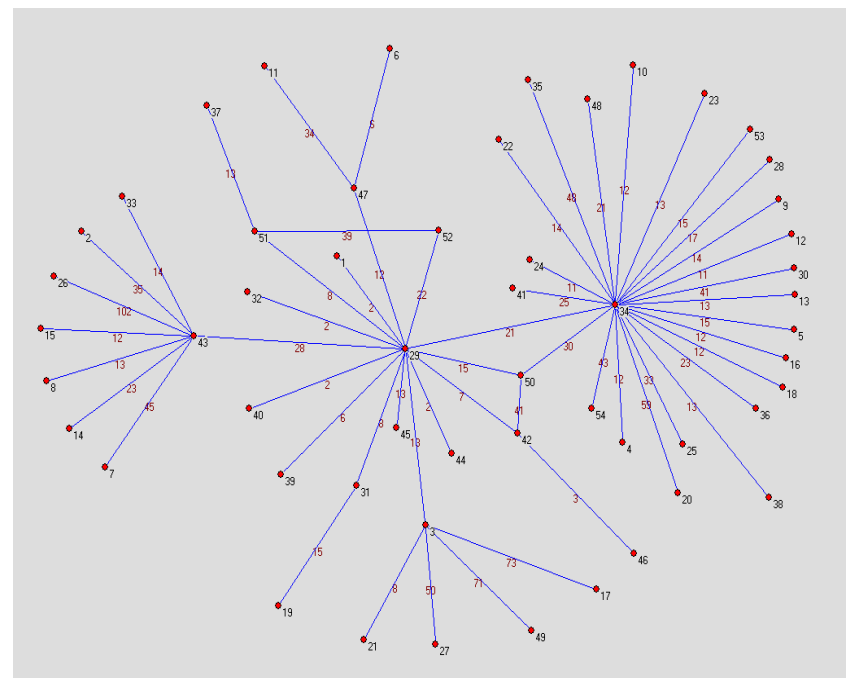

Figure 10. Network for identifying membership in the indie music blog

It now appears evident that there exist social structures that can indicate possible community in this network. Intuitively, we can use the structure of a star network for determining possible communities. We visualize this in Figure 11.

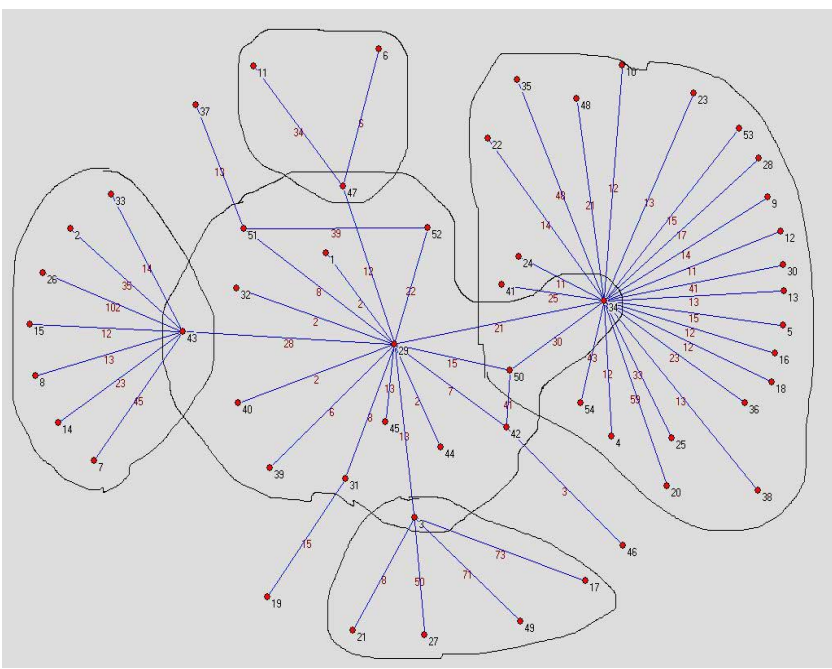

Figure 11. Possible communities extracted using star network structure from indie music blog network

\subsubsection{Influence}

Blogs that can be of influence in the indie music blog network are the ones that can act as brokers. From Figure 11, blogs 43, 34, 3 and 47 were identified as the brokers because they are the bridges between members in their group (which we have highlighted) and the indie music blog. Therefore, the star networks of blogs 43, 34,3 and 47 can be possible communities.

\subsubsection{Reinforcement of needs}

From our social hypertext model, we identified reciprocal links where each directed link had a frequency $>m$ as the structure for reinforcement of needs, where $m$ was considered the need threshold. For the indie music blog, we decided to choose $m$ to be 2 as the minimum frequency for possibly expressing need. The blogs that had the frequency of directional links greater than 2 for both inlinks and outlinks is the same as in Figure 10.

\subsubsection{Shared emotional connection}

The structures for identifying shared emotional connection according to our proposed model are triangles and completely connected graphs. From Figure 10, we found triangles as completely connected graphs in the indie music blog network. They were extracted and are illustrated in the diagram of Figure 12 below.

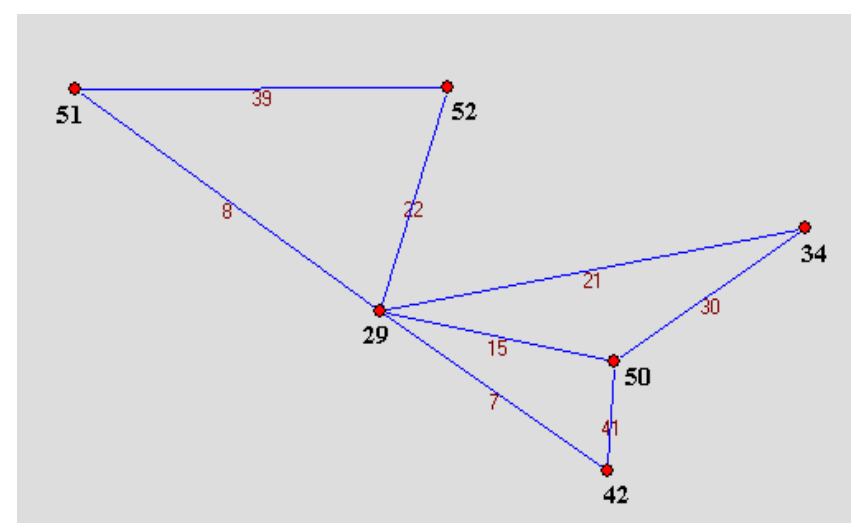

Figure 12. Communities found by identifying shared emotional connection in the indie music blog 
From Figure 12, we found the existence of 3 triangles that included the indie music blog (blog 29). From the numbers on the edges, there seemed to be frequent conversation, with the least of them occurring between the indie music blog (blog 29) and blogs 51 and 42. As well, there were some triangles whose edge weights were higher than edge weights in other triangles. This suggests that there could be different strengths of communities. For example, the triangle containing the indie music blog (blog 29) and blogs 34 and 50 could be considered as a stronger community than the triangle containing blogs 29, 42 and 50, because the average frequency of conversation is higher.

By combining all possible communities found from applying our methodology as above, we arrive at the network diagram of Figure 13.

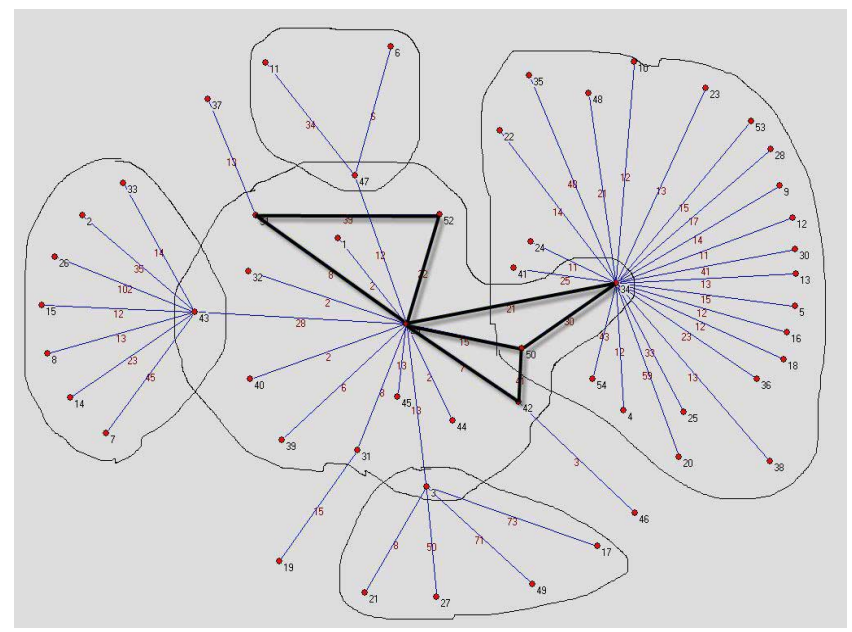

Figure 13. Communities identified using visualization indicators for sense of community

\subsection{Synthesis of Results}

The sixth step in our research framework from Figure 1 is to perform the synthesis. Here, we analyzed the sense of community scores to determine which blogs from the network of Figure 13 above in the structural analysis step, were indeed part of a community. For the bloggers that participated in the survey, we computed the scores for the sense of community subscales and the total sense of community index. We also summarize the structures for visualization indicators of the structural analysis from Section 4.4 in this section. As part of the structural analysis, we also computed the degree centrality, betweenness centrality, closeness centrality and identified $k$-cores as the social network analysis indicators. Table 3 summarizes the results.

The table lists 6 blogs out of the 15 bloggers who responded to the survey. These 6 blogs (anonymized as 45, 50, 34, 343, 605 and 606) are the MSN Spaces blogs of which 4 blogs (45, 50, 34 and 343) are in the network of the indie music blog confined to only MSN Spaces (Figure 8), while the rest of the blogs (605 and $606)$ were nowhere to be found. We reasoned that blogs 605 and 606 were not found in the network of Figure 8 because the bloggers of blogs 605 and 606 only read posts and comments and did not write any comments to the indie music blog. We now analyze for sense of community according to the SOC index and structural analysis.
Table 3. Results from the sense of community survey and structural analysis

\begin{tabular}{|c|c|c|c|c|c|c|}
\hline Analysis step & Blog number & & & & & \\
\hline & 45 & 50 & 34 & 343 & 605 & 606 \\
\hline \multicolumn{7}{|l|}{ Step \#4: SOC index } \\
\hline Membership & 7 & 10 & 11 & 5 & 7 & 4 \\
\hline Influence & 9 & 12 & 11 & 5 & 9 & 5 \\
\hline Need & 9 & 13 & 12 & 8 & 9 & 10 \\
\hline Shared emotion & 11 & 13 & 10 & 8 & 9 & 7 \\
\hline Total SOC index & 36 & 48 & 44 & 26 & 34 & 26 \\
\hline \multicolumn{7}{|l|}{ Step \#5: Structural analysis } \\
\hline \multicolumn{7}{|l|}{ Visualization indicator } \\
\hline Membership & Star network & Star network & Star network & None & None & None \\
\hline Influence & Not a broker & Broker & Broker & None & None & None \\
\hline \multicolumn{7}{|c|}{ Need } \\
\hline $\min f$ & 13 & 7 & 11 & None & None & None \\
\hline $\max f$ & 13 & 41 & 59 & None & None & None \\
\hline Shared emotion & None & $\begin{array}{l}\text { Part of } 2 \\
\text { triangles } \\
\text { which are } \\
\text { completely } \\
\text { connected } \\
\text { graphs }\end{array}$ & $\begin{array}{l}\text { Part of } 1 \\
\text { triangle } \\
\text { which is } \\
\text { completely } \\
\text { connected } \\
\text { graph }\end{array}$ & None & None & None \\
\hline \multicolumn{7}{|c|}{ SNA indicator } \\
\hline $\begin{array}{r}\text { Degree } \\
\text { centrality } \\
\text { (normalized) }\end{array}$ & 0.0074627 & 0.0439469 & 0.0812604 & 0.000829 & & \\
\hline $\begin{array}{r}\text { Betweenness } \\
\text { centrality } \\
\text { (normalized) }\end{array}$ & 0.0013794 & 0.016066 & 0.0760532 & 0 & & \\
\hline $\begin{array}{r}\text { Closeness } \\
\text { centrality } \\
\text { (normalized) }\end{array}$ & 0.3528379 & 0.3802018 & 0.3880309 & 0.290602 & & \\
\hline$k$-core & None & $\begin{array}{l}\text { Part of two } \\
\text { 2-cores }\end{array}$ & $\begin{array}{l}\text { Part of one } \\
\text { 2-core }\end{array}$ & None & & \\
\hline
\end{tabular}

\subsubsection{Sense of community survey results}

We found that blogs 45, 50 and 34 from Table 3 were in the set of communities which we identified from our model in Figure 11, while the rest of the other blogs were not in Figure 11. By examining the total SOC index, we discovered that the total SOC index ranged from 36 to 48 for blogs within our identified communities. The rest of the other blogs $(343,500$ and 422) had a total SOC index of 26, 34 and 26 respectively. This could then suggest that one of the criteria for determining if a blog is in a sense of community is that its total SOC index must be greater than 35. On closer examination of the blogging behaviour of 45, 50 and 34 from the survey revealed the following.

Blogger 45 blogged at least once a day, and he blogged to meet people, to seek other people's feedback, and to express his opinions. He read blogs once a day and sometimes made comments on other people's blogs. From Figure 11, he only connected to the indie music blog and no one else. We also noticed that blogger 45's membership, influence, reinforcement of needs, and shared emotional connection scores were low compared to bloggers 50 and 34. As a result, we can conclude that 45 is part of a weak community formed by the indie music blog.

Blogger 50 updated his blog a few times per week, and he blogged to keep a record of his thoughts and opinions. He read blogs a few times per week, read blogs referred to by others, and usually wrote comments on the blogs that he read. From Figure 11 , he connected to blog 34, 42 and 29 (indie music blog) at least 15 times (30, 41 and 15 respectively). Due to his blogging behaviour, he had higher scores of membership, influence, reinforcement of needs and shared emotional connection than blogger 45. His total of sense of community index was also much higher than blogger 45 . We conclude that 50 is part of a strong community formed by the indie music blog. 
Blogger 34 updated his blog a few times per week, and he blogged to seek other people's feedback and to express his opinions. He read blogs once a day and usually left comments on the blogs that he read. Due to his blogging behaviour, we would expect that he would make many connections and would be a likely candidate to be part of a community. From Figure 11, he connected to the indie music blog and to blog 50. In addition, he also connected with many other bloggers in his own community, identified by the star network. The frequency of connections was high with the minimum being 11 and the maximum being 59 . He had similar scores for membership, influence, reinforcement of needs, and shared emotional connection, compared to blogger 50 but had a lower total sense of community index. However, from the connections and structure in Figure 11, he had stronger community than blogger 50 . We conclude that he is part of a strong community, identified by the star network and the triangle that he is a member of.

Examining the other blogs $(343,605$ and 606) that were not part of the set of possible communities in Figure 11, we found that 343 and 606 had the lowest total SOC index with a score of 26. For 343 , we found from the survey that he blogged to release emotional tension and to express opinions, he read blogs once a day, and he read blogs referred to by others. However, sometimes he did not leave comments on the blogs that he read. As a result, we expect that he would not form many conversations which explained the low total SOC index. For readers of the indie music blog like 605 and 606 that did not comment, they will derive value from the blog but will not form any part of a community since they are not participants in the conversations. The low total SOC scores (34 and 26 for blog 605 and 606 respectively) reflect their relative lack of participation in the community.

\subsubsection{Structural analysis results}

Comparing the MSN Spaces blogs from the survey to the set of possible communities in Figure 11 according to the visualization, yielded the structures as tabulated in Table 3 . We used the results of visualization and social network analysis from Table 3, to confirm if the blogs were indeed part of any community.

Blog 45 is part of a star network that is centered around the indie music blog (29) with the second lowest degree centrality out of all the MSN Spaces blogs from the survey. This confirms that he has feelings of membership. He did not have feelings of influence because he was not a broker and had the second lowest betweenness centrality. He appeared to have feelings of need from the frequency of connections being 13 and had the second lowest closeness centrality. He had no shared emotional connection because he was not part of any triangles or completely connected graphs and he was not part of a $k$-core. His degree centrality was the second lowest out of all the MSN Spaces blogs from the survey. As a result, blog 45 is not part of a community.

For blog 50, he had feelings of membership because he was at the center of the star network with blogs 29, 34 and 42, and had the second highest degree centrality. He influenced others because he was a broker with the second highest betweenness centrality. $\mathrm{He}$ had feelings of need with the maximum frequency being 41 and had the second highest closeness centrality. He had shared emotional connection because he was part of a set of 2 triangles with the first triangle containing 29 and 34, and the second triangle containing 29 and 42, which happened to be 2-cores. We can validate that 50 is part of a strong community.
For blog 34, we found that he had feelings of membership because he was at the center of his star network and had the highest degree centrality out of all the blogs. He influenced others because he acted as a broker and had the highest betweenness centrality. He had feelings of need because he had many connections to the same blogger (with the largest being a frequency of 59) and had the highest closeness centrality. He had shared emotional connection because he was part of a triangle containing 29 and 50 which is a 2-core. We can say that 34 is part of a strong community.

Blogs 343, 605 and 606 showed no structures of membership, influence, need, or shared emotional connection. Specifically, blog 343 had the lowest degree centrality, betweenness centrality, and closeness centrality. Blog 343 also had no $k$-core. Since blogs 605 and 606 were readers and did not comment, there was no calculation of any centrality measures or identification of $k$ cores for them.

\subsubsection{Measures of community}

From the results, we summarize possible measures of community. Blogs 45, 50 and 34 (which are part of the possible communities in Figure 11) had higher normalized degree centrality than those blogs that were not a part of the community. This suggests that there may be a threshold normalized degree centrality in which a blog is considered part of a community, and in our case, it might be around 0.0439469 or greater.

Blogs 50 and 34 had the highest betweenness centrality, and we validated that they were indeed brokers and can be members of a community. This suggests that there may be a threshold normalized betweenness centrality that indicates whether a blog is a broker and can be part of a community. In our case, the threshold for the normalized betweenness centrality might be around 0.016066 or greater.

The blogs with the highest normalized closeness centrality were 45,50 and 34 and they were part of the communities we identified in Figure 11. There maybe a threshold normalized closeness centrality which a blog must have in order to be considered a member of a community. In our case, the threshold for the normalized closeness centrality might be around 0.3802018 or greater.

\subsection{Discussion}

It is important to note that even though the respondents to the survey were limited in number, our method for identifying and measuring community can in fact scale beyond the limited test arena, because structural analysis is easily performed using the visualization tool and centrality measures are easy to calculate. The sense of community survey is easily employed for small samples and is used to initially calibrate the structures and measures for sense of community. Once this has been completed, then the sense of community survey is not required for larger samples, hence all that is required is to perform structural analysis.

In addition, our method does not distinguish between subcommunities or rival communities, but rather identifies only generic communities. This is because the type of community is dependent on its role and position in the social network, which is subjective and relative to other communities. 
The membership patterns from the structural analysis of our method encode the links between members via comments, but do not take into account the nature of those comments. For example, the membership patterns will not detect that a member of the community is a commentator whom everyone hates. We do not address the content analysis of the links between the blogs from the comments themselves, because our intent is to identify sense of community in a generic fashion and not to distinguish between agreement and disagreement in a community.

While the present results are promising, further research is needed to apply our methodology and model to larger and more popular blogs.

\section{CONCLUSIONS}

In this paper we examined the properties of blogs as a form of social hypertext. We developed a method for identifying community in blogs, and in similar forms of social hypertext. This method includes the use of visualizations and centrality measures based on networking structure, and measures of strength of community based on survey data. With this method we proposed a model of synthesizing structural and survey data in social hypertext by creating an alignment between network centrality measures on the one hand, and the four sense of community subscales on the other.

We then reported on a case study designed to examine formation of virtual community for a working blog. We tracked the beginnings of virtual community forming around a new blog. The network of reciprocally linked blogs was found to form a set of connected stars which we hypothesized to be typical of blogs in an early stage of development. We then presented a simple analysis involving six blogs, all of which were authored by readers of the research blog that was the centre of the community under consideration. Three of the blogs showed evidence of being part of the community, in terms of the evidence of community formation visible in the network visualization, and in terms of both the social network analytic centrality measures used, and the strength of community scale and its subscales. In contrast, a fourth blog that was visually separated from the others was also found to have markedly lower centrality measures, and sense of community scores. Sense of community measures were also collected for two additional blogs whose authors provided sense of community data, but for which the network analytic measures were not calculated. These two blogs also showed comparatively low strength of community scores. Of the three better-connected blogs, one blog had lower centrality and SOC scores. In contrast to the other two, this blog was not a broker and did not participate in any $k$-cores within the network surrounding our research blog.

The present results provide preliminary findings concerning the applicability of the proposed method for community in hypertext. In our study, strength of community measures were well aligned with the network structure based on centrality measures. The social hypertext model described in this paper is offered as a potentially useful way of measuring and describing measures of community for blogs in general. While it seems likely that overall sense of community and network centrality measures are closely aligned as measures of community, it remains to be seen how the sense of community subscales, and the different centrality measures, can be used to tease apart differing forms of community in blogs.
In this study we focused on the community of blogs surrounding a particular blog. Future research should distinguish between core communities of blogs and people immediately linked to a blog, and extended communities that may be accessible through brokers that are directly attached to the blog. In addition, there may be higher level communities within which specific communities such as those surrounding a particular blog are embedded. Models of social hypertext should eventually also address the issue of higher level communities.

\section{REFERENCES}

[1] Allen, J. and Dillman, D. Against all Odds: Rural Community in the Information Age. Westview Press, Boulder, CO, 1994.

[2] Chin, A. and Chignell, M. Finding Evidence of Community from Blogging Co-citations: A Social Network Analytic Approach. In Proceedings of $3^{\text {rd }}$ IADIS International Conference Web Based Communities 2006 (WBC06) (San Sebastian, Spain, Feb. 26-28, 2006), 2006, 191-200.

[3] Blanchard, A. The effects of dispersed virtual communities on face-to-face social capital. In M. Huysman \& V. Wulf (Eds), Social capital and information technology. MIT Press, Cambridge, USA, 2003.

[4] Blanchard, A. Blogs as Virtual Communities: Identifying a Sense of Community in the Julie/Julia Project. Into the Blogosphere: Rhetoric, Community and Culture. http://blog.lib.umn.edu/blogosphere, 2004.

[5] Blanchard, A. and Markus, M. The Experienced "Sense" of a Virtual Community: Characteristics and Processes. The DATA BASE for Advances in Information Systems, 35, 1, 2004.

[6] Borgatti, S. P. et al., Ucinet for Windows: Software for Social Network Analysis. Analytic Technologies, Harvard, USA, 2002.

[7] Burroughs, S. M., and Eby, L. T. Psychological sense of community at work: An explanatory framework. Journal of Community Psychology, 26 (1998), 509-532.

[8] Burt, R.S., and M. Minor, Applied Network Analysis: A Methodological Introduction, Newbury Park: Sage, 1983

[9] Chavis, D. Sense of Community Index. Association for the Study and Development of Community, http://www.capablecommunity.com/pubs/SCIndex.PDF.

[10] Chavis, D. and Wandersman, A. Sense of community in the urban environment: A catalyst for participation and community development. American Journal of Community Psychology, Vol. 18, No. 1 (Feb 1990), 55 - 81.

[11] de Nooy, W. et al. Exploratory Social Network Analysis with Pajek. Cambridge University Press, New York, USA, 2005.

[12] Efimova, L. and Hendrick, S. In Search for a Virtual Settlement: An Exploration of Weblog Community Boundaries. https://doc.telin.nl/dscgi/ds.py/Get/File46041/weblog_community_boundaries.pdf, 2005.

[13] Efimova, L. et al. Finding "the life between buildings": An approach for defining a weblog community, AOIR Internet Research 6.0: Internet Generations, Chicago, 2005. 
[14] Erickson, T. WWW as Social Hypertext. Communications of the ACM, Vol. 39, No. 1 (January 1996), 15-17.

[15] Fisher, D. Using Egocentric Networks to Understand Communication. IEEE Internet Computing, Vol. 9, No. 5 (2005), 20-28.

[16] Flake, G. et al. Self-Organization and Identification of Web Communities. IEEE Computer, Vol. 35, No. 3 (2002), 66-71.

[17] Freeman, L. C. Centrality in Social Networks: Conceptual Clarification. Social Networks 1: 1978/79, 215-239.

[18] Herring, S.C. et al. Conversations in the Blogosphere: An Analysis "From the Bottom Up". In Proceedings of the Thirty-Eighth Hawai'i International Conference on System Sciences. Los Alamitos, USA, 2005, 107-118.

[19] Jones, Q. Virtual-communities, virtual settlements and cyber-archaeology: A theoretical outline. Journal of Computer Supported Cooperative Work, Vol. 3, No. 3, 1997.

[20] Kim, A. J. Community Building on the Web: Secret Strategies for Successful Online Communities. Peachpit Press, Berkeley, CA, 2000.

[21] Kumar, R. et al. On the Bursty Evolution of Blogspace. In Proceedings of the 12th International Conference on World Wide Web, New York, USA, 2003, 568-576.

[22] Kumar, R. et al. Trawling the Web for emerging cybercommunities. Computer Networks. Amsterdam, Netherlands, 1999.

[23] Kleinberg, J. Authoritative sources in a hyperlinked environment. In Proc. 9th ACM-SIAM Symposium on Discrete Algorithms, 1998.

[24] Lanphear, B.P. et. al. Community Characteristics Associated With Elevated Blood Lead Levels in Children. Pediatrics, Vol. 101, No. 2, 264-271, 1998.

[25] Maclaran, P. and Catterall, M. Researching the Social Web: Marketing Information from Virtual Communities. Marketing Intelligence and Planning, Vol. 20, No. 6, 319326, 2002.

[26] McMillan, D. W. and Chavis, D. M. Sense of community: A definition and theory. Journal of Community Psychology, Vol. 14, No. 1 (1986), 6-23.
[27] Merelo-Guervos et al. Mapping weblog communities. http://arxiv.org/pdf/cs.NE/0312047, 2004.

[28] Nardi, B.A. et al. Why we blog. In Communications of the $A C M$, Vol. 47, No. 12, 2004, 41-46.

[29] Rheingold, H. The virtual community: Homesteading on the electronic frontier. Addison-Wesley, Toronto, Canada, 1993.

[30] Ten Thij, E. et. al. Success Factors of (Dutch) Online Dance Communities: A Validation of Website Features For Social Interaction. In Proceedings of $3^{\text {rd }}$ IADIS International Conference Web Based Communities 2006 (WBC06) (San Sebastian, Spain, Feb. 26-28, 2006), 2006, 201-210.

[31] Tonnies, F. Community and Society. Courier Dover Publications, United Kingdom, 2002.

[32] Tyler, J. R. et. al. E-Mail as Spectroscopy: Automated Discovery of Community Structure within Organizations. The Information Society, Vol. 21, No. 2, 2005, 143 - 153.

[33] Valdez, F. and Chignell, M. Browsing Models for Hypermedia Databases. In Proceedings of the Human Factors Society, 32nd Annual Meeting, Santa Monica, CA, 1988, 196-200.

[34] Wei, C. Formation of norms in a blog community. Into the Blogosphere: Rhetoric, Community and Culture of Weblogs, University of Minnesota, Minnesota, USA, 2004.

[35] Wellman, B. Computer networks as social networks. Science, 293, 5537 (September 2001), 2031 - 2034.

[36] Wellman, B. and Guilia, M. Net Surfers don't ride alone: Virtual communities as communities. In B. Wellman (Ed.), Networks in the global village: Life in contemporary communities, Westview Press, Boulder, USA, 1999.

[37] Wellman, B. Networks in the Global Village: Life in Contemporary Communities. Westview Press, Boulder, CO, 1999.

[38] Wikipedia. Blogs. http://en.wikipedia.org/wiki/Blogs, 2006.

[39] Wikipedia. Community. http://en.wikipedia.org/wiki/Community, 2006. 